\title{
Study of Congestion of the Road Traffic at Railway Crossings
}

\author{
Darshan M. Mali ${ }^{1}$, Prof. Nekzad F. Umrigar ${ }^{2}$, Prof. N. A Patel ${ }^{3}$ \\ Student M. Tech, Trans. Engg, BVM College, Gujarat, India ${ }^{1}$ \\ Assistant Prof in Civil Engg Dept, BVM Engg College, Gujarat India ${ }^{2}$ \\ Lecture, Civil Engg Dept, BBIT, V.V. Nagar, Gujarat, India ${ }^{3}$
}

\begin{abstract}
People of Anand and vallabh vidyanagar are facing acute traffic and delay problems at railway crossing roads. The main reason for this problem is passage of more number of trains from here which results in closure of railway gate for longer periods of time. People have to wait for several minutes to pass through this railway crossing. In the study area all the railway crossings are not having the median or wide roadway so creating more congestion at the time of approaching the train. In this paper various railway crossings of Anand and Vallabh vidyanagar are visited and various primary surveys are conducted. As a part of study analysis is carried out.
\end{abstract}

Keywords: railway crossing, congestion, delay, classified volume count.

\section{INTRODUCTION}

Vehicular traffic on roads has grown at an uncontrollable rate over the years making travel chaotic, tiring, and time delaying also unsafe one. It is common thing that when two roads intersect, junction appears and because of both the intersecting roads in the same horizontal plane. These are junctions from where traffic from different directions converge and causing traffic congestion, delay and also accidents. The main reason for this traffic delay is overfilling at junctions due to the increased density of traffic from both directions of railway crossing.

To avoid subsequent congestion, flyover or road over bridge were designed which have partially solved the problem of congestion and accidents. As traffic is not only problem of mega cities but also the problem of small developing cities in India. Mega cities are well planned having transport system also well - equipped on other hand the developing cities are not so well planned. That's why if planning of small city is taken in to account it may create problems. As example if any developing city has residential area divided in small part and if some part of city is generating employment, providing business and educational facilities for people of about $1 / 2$ population of city than it can create traffic problem due trip generation from different area of city toward that area.

People of vallabh vidyanagar and Anand town are facing acute traffic problem at various railway crossings. People have to wait for several minutes to pass through these railway crossings. They are facing delay maany times a day. Also because of more congestion at railway crossing after opening the gate they are facing more delay at crossing.
In developing country like India, the traffic is heterogeneous means mixed traffic flow, with vehicles of wide-ranging static and dynamic characteristics. Also the size of vehicles varies widely, and the lateral and longitudinal pl acement of vehicles on the carriageway are complex, with no discernible lane discipline. The saturation flow, which is the maximum possible value of flow through various railway crossings approach, is an important factor in the analysis of delay.

\section{STUDYAREA}

Anand is a fast growing medium town which has a major educational and cooperative type setup and also Vallabh Vidyanagar. The traffic problem in the approach roads in the Vallabh Vidyanagar have increased due to increased vehicular traffic between Anand-Vallabh Vidyanagar. The internal road traffic due to pressure from daily commuters mostly students, business people, workers and related persons increase the problems on the roads such as traffic, parking and accidents.

The major access is also used by the public buses often passing from outside the city to another parts, creates problems for the regular traffic movements. Because these factors two railway crossings are facing acute traffic problems like congestion, delay. Meanwhile people at Vallabh Vidyanagar's railway crossing at Janta Chokdi are facing traffic congestion and delay due to A.D.I.T. college campus, G.I.D.C. located in Vallabh Udhognagar.

\section{DATACOLLECTION}

Classified volume count survey 
International Advanced Research Journal in Science, Engineering and Technology

ISO 3297:2007 Certified

Vol. 4, Issue 3, March 2017

TABLE1 Janta Chokdi Railway Crossing (morning peak hours)

\begin{tabular}{|c|c|c|c|c|}
\hline Direction & & To Jaanta Chokdi & To Sardar Patel Statue & \multirow{2}{*}{ Total } \\
\cline { 3 - 5 } Time & Unit & $\begin{array}{c}\mathbf{8 . 0 0} \text { to } \\
\mathbf{9 . 0 0 a m}\end{array}$ & $\begin{array}{c}\mathbf{8 . 0 0} \text { to } \\
\mathbf{9 . 0 0 a m}\end{array}$ & 1735 \\
\hline \multirow{2}{*}{ 2 wheelers } & Vehicle & 933 & 802 & 867 \\
\cline { 2 - 5 } & PCU & 466.5 & 401 & 274 \\
\hline \multirow{2}{*}{ 3 wheelers } & Vehicle & 189 & 95 & 270 \\
\cline { 2 - 5 } & PCU & 151.2 & 118.8 & 499 \\
\hline \multirow{2}{*}{ 4 wheelers } & Vehicle & 302 & 197 & 109 \\
\cline { 2 - 5 } & PCU & 302 & 197 & 327 \\
\hline \multirow{2}{*}{ Bus/truck } & Vehicle & 60 & 49 & \\
\cline { 2 - 5 } & PCU & 180 & 147 & \\
& & & &
\end{tabular}

TABLE2 janta chokdi railway crossing (evening peak hours)

\begin{tabular}{|c|c|c|c|c|}
\hline Direction & \multirow[b]{2}{*}{ Unit } & To Jaanta Chokdi & 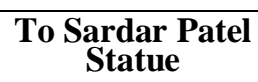 & \multirow[b]{2}{*}{ Total } \\
\hline Time & & $\begin{array}{l}6.00 \text { to } \\
7.00 \mathrm{pm}\end{array}$ & $\begin{array}{l}6.00 \text { to } \\
7.00 \mathrm{pm}\end{array}$ & \\
\hline \multirow{2}{*}{2 wheelers } & Vehicle & 950 & 1008 & 1958 \\
\hline & PCU & 475 & 504 & 979 \\
\hline \multirow{2}{*}{3 wheelers } & Vehicle & 129 & 220 & 349 \\
\hline & PCU & 103.2 & 176 & 279.2 \\
\hline \multirow{2}{*}{4 wheelers } & Vehicle & 247 & 340 & 687 \\
\hline & PCU & 247 & 340 & 687 \\
\hline \multirow{2}{*}{ Bus/truck } & Vehicle & 47 & 61 & 108 \\
\hline & PCU & 141 & 183 & 324 \\
\hline
\end{tabular}

TABLE3 Ganesh Chokdi Railway Crossing (Morning Peak

\begin{tabular}{|c|c|c|c|c|}
\hline \multirow{2}{*}{ Direction } & \multirow{2}{*}{ Unit } & $\begin{array}{c}\text { Toganesh } \\
\text { chokdi }\end{array}$ & To amul dairy & \multirow{2}{*}{ Total } \\
\cline { 3 - 4 } Time & $\begin{array}{c}\mathbf{8 . 0 0} \text { to } \\
\mathbf{9 . 0 0 a m}\end{array}$ & $\begin{array}{c}\mathbf{8 . 0 0} \text { to } \\
\mathbf{9 . 0 0 a m}\end{array}$ & \\
\hline \multirow{2}{*}{ 2 wheelers } & Vehicle & 422 & 756 & 1178 \\
\cline { 2 - 4 } & PCU & 211 & 378 & 589 \\
\hline \multirow{2}{*}{3 wheelers } & Vehicle & 365 & 451 & 816 \\
\cline { 2 - 4 } & PCU & 292 & 360.8 & 652.8 \\
\hline \multirow{2}{*}{ 4 wheelers } & Vehicle & 181 & 210 & 391 \\
\cline { 2 - 4 } & PCU & 181 & 210 & 391 \\
\hline \multirow{2}{*}{ Bus/truck } & Vehicle & 75 & 53 & 128 \\
\cline { 2 - 4 } & PCU & 225 & 159 & 384 \\
\hline
\end{tabular}

TABLE 4 Ganesh Chokdi Railway Crossing (Evening Peak Hours)

\begin{tabular}{|c|c|c|c|c|}
\hline Direction & \multirow[b]{2}{*}{ Unit } & To Amul Dairy & To Ganesh Chokdi & \multirow[b]{2}{*}{ Total } \\
\hline Time & & $\begin{array}{l}6.00 \text { to } \\
7.00 \mathrm{pm}\end{array}$ & $\begin{array}{l}6.00 \text { to } \\
7.00 \mathrm{pm}\end{array}$ & \\
\hline 2 & Vehicle & 736 & 619 & 1355 \\
\hline Wheelers & PCU & 368 & 309.5 & 677 \\
\hline
\end{tabular}


ISO 3297:2007 Certified

Vol. 4, Issue 3, March 2017

\begin{tabular}{|c|c|c|c|c|}
\hline $\mathbf{3}$ & Vehicle & 185 & 170 & 355 \\
\cline { 2 - 5 } Wheelers & PCU & 148 & 136 & 284 \\
\hline \multirow{4}{*}{ Wheelers } & Vehicle & 189 & 180 & 369 \\
\cline { 2 - 5 } Bus/truck & PCU & 189 & 180 & 369 \\
\cline { 2 - 5 } & Vehicle & 25 & 22 & 47 \\
\hline \multirow{2}{*}{ PCU } & 75 & 66 & 141 \\
\hline
\end{tabular}

From the table 2 it can be observed that the at level crossing closed continuously for 20 minutes due to repetitive from total of 1958 from janta chokdi total of 1008 vehicles shunting operations of trains. But it also observed in the travels in the crossing on the otherhand total of 950 morning peak and evening peak hours. This is causing vehicles travel in opposite direction. Which is the hazardous

almost equal in both directions. From the table it can be situation at this crossing. The gate closure detail is also observed that movement of two wheelers is higher summarized below in Table.

followed by three wheelers and four wheelers. 1963 PCU in morning peak hours and 2269.2 PCU in evening peak hours.

From the table 3 it can be observed that the at level crossing from total of 1178 vehicles from Ganesh chokdi total of 756 vehicles travels in the crossing, on the other hand total of 422 vehicles travel in opposite direction. In which former is the higher.

2016.8 pcu From the table it can be also observed that movement of two wheelers is higher followed by three wheelers and four wheelers.

It's observed from the tables above that there are more numbers of three wheelers at ganesh chokadi railway crossing compared to four wheelers. And also there are more numbers of four wheelers at janta chokdi railway crossing as compared to three wheelers.

Frequency and duration of gate closure:

From the study, there are total 16 numbers of trains passing through this line. In which all 16 numbers of passenger trains passing through this level crossing. The gate closures per day were observed

2 hours and 43 minutes. It was observed that due to shunting operation of trains. Janta rail crossing is frequently closing this causing maximum of inconvenience

TABLE 5 Frequency and duration of gate closure

\begin{tabular}{|c|c|c|}
\hline \multicolumn{2}{|c|}{$\begin{array}{l}\text { Time duration(24 hour } \\
\text { format) }\end{array}$} & \multirow{2}{*}{$\begin{array}{l}\text { Total } \\
\text { Time (hrs.) }\end{array}$} \\
\hline From & To & \\
\hline $5: 00$ & $5: 10$ & $0: 10$ \\
\hline $6: 00$ & 6:09 & 0:09 \\
\hline 7:08 & $7: 20$ & $0: 12$ \\
\hline 8:05 & $8: 14$ & 0:09 \\
\hline $9: 25$ & $9: 35$ & $0: 10$ \\
\hline $10: 20$ & $10: 29$ & 0:09 \\
\hline $11: 15$ & 11:25 & $0: 10$ \\
\hline $12: 15$ & $12: 24$ & 0:09 \\
\hline $13: 40$ & $13: 49$ & 0:08 \\
\hline $14: 35$ & $14: 45$ & $0: 10$ \\
\hline $15: 38$ & $15: 45$ & 0:07 \\
\hline $16: 38$ & $16: 45$ & $0: 07$ \\
\hline 18:05 & 18:14 & 0:09 \\
\hline 19:00 & 19:10 & $0: 10$ \\
\hline $20: 15$ & $20: 27$ & $0: 12$ \\
\hline $21: 10$ & $21: 19$ & 0:09 \\
\hline \multicolumn{2}{|c|}{ Total (Hrs.) } & $2: 43$ \\
\hline
\end{tabular}

to the road users. On the day of the survey the gate was

TABLE 6 Vehicle Affected By Gate Closure

\begin{tabular}{|l|l|l|l|l|l|l|}
\hline Direction & $\begin{array}{l}\text { Janta Chokdi } \\
\text { To } \begin{array}{r}\text { Sardar } \\
\text { Patel Statue }\end{array}\end{array}$ & $\begin{array}{l}\text { Sardar Patel } \\
\text { Statue ro } \\
\text { Janta Chokdi }\end{array}$ & Total & & & \\
\hline & Veh. & PCU & Veh. & PCU & Veh. & PCU \\
\hline 2Wheelers & 140 & 70 & 70 & 35 & 210 & 105 \\
\hline 3Wheelers & 30 & 24 & 19 & 15.2 & 49 & 39.2 \\
\hline 4Wheelers & 41 & 41 & 21 & 21 & 62 & 62 \\
\hline Bus/Truck & 5 & 15 & 2 & 6 & 7 & 21 \\
\hline Total & 266 & 150 & 112 & 77.2 & 378 & 227.2 \\
\hline
\end{tabular}

Location: Janta Chokadi Railway crossing (Morning Peak Hour) 
Delay Time

It begins when the vehicle is fully stopped and ends when the vehicle in traffic flows normally. Average stoppedtime delay is the average for all vehicles during a specified time period. The delay observed maximum was 14.30 minutes that was at ganesh chokdi as a pilot survey.

\section{CONCUSION}

From the results of the analysis and from the field observation of traffic characteristics it may be concluded that:

Under saturated flow conditions, the inter correlation of vehicle groups, in addition to intersection geometry and average vehicular composition, is an important factor influencing the value of the passenger car unit (PCU) for different kinds of vehicles.

Janta chokdi railway crossing facing traffic having total highest PCU 2269.2. so more numbers of people have to face congestion and delay as compared to ganesh chokdi railway crossing having PCU 2016.2 and also people passing through Janta chokdi railway crossing are most of four wheelers as compared to three wheelers causing more congestion and total delay. Also crossing gate closure duration total of 2:43 hours during the whole day causing more stopped delay. Also in vehicles affected by gate closure there are higher number of four wheelers than three wheelers caused increase in queue length at Janta chokdi railway crossing at vidyanagar railway station.

\section{REFERENCES}

[1] Hanseon Cho, Ph.D. And Laurence R. Rilett, Ph.D., Improved Transition Preemption Strategy For Signalized Intersections Near At-Grade Railway Grade Crossing, 10 .

[2] Kuldip.B.Patel, Anand D. Sapariya Pradeep P. Lodha, Feasibility Study For Planning A Fly- Over Bridge Over Railway Crossing At Vijalpore Road, Navsari, Volume 2, Issue 1, January -2015

[3] Lei Yu2, Fenf'iang', Leonard Munghor", Xin Wang, And Anchalee, Application Of Its Technology To Improve Highway-Rail Grade Crossing Safet, Traffic And Transportation Studies.

[4] Parth M. Pande, Saurabh Patel, Jaimin Solanki, "Evaluation Of Delay And Level Of Service For Signalized Intersection Of Urban Area", Issn: 0975

6744| Nov 15 To Oct 16 | Volume 4, Issue 1

[5] Vivek Singhal , Dr. S.S. Jain, Safety Information System Of Indian Unmanned Railway Level Crossings, E-Issn: 22781684,P-Issn: 2320-334x, Volume 12, Issue 4 Ver. Iii (Jul. Aug.2015), Pp 70-80

[6] XinChen, Zhaohu Xu, Xuewen Chen, Yuanyuan Zhang , Analysis of The Railway Crossing Traffic In Jinzhou Urban District , Ictis 2013 @ C Asce 2013

[7] Xiangyang Li, Lin Cheng, Traffic Congestion Research Of Road And Railway Intersection, Icctp 2011 @ ASCE 2011 